\title{
ASSESSMENT OF EFFICIENCY OF COMPOST PREPARED FROM ANIMAL WASTE IN THE REDUCTION OF TOTAL PETROLEUM HYDROCARBON IN CRUDE OIL IMPACTED SOIL
}

\author{
ADEBOLA ADEKUNLE ${ }^{1 *}$, IHEOMA ADEKUNLE ${ }^{2}$, SUHAIB AROGUNDADE $^{3}$ \\ ${ }^{1}$ Department of Civil Engineering, Federal University of Agriculture, Abeokuta, Ogun \\ State, Nigeria \\ ${ }^{2}$ Department of Chemistry, Federal University Otuoke, Bayelsa State, Nigeria \\ ${ }^{3}$ School of Civil Engineering, University of Leeds, United Kingdom
}

\begin{abstract}
The aim of this study was to investigate the potentials of composted animal waste in biodegradation of hydrocarbon in a cost-effective, efficient, and environmentalfriendly manner. The contaminated soil sample was collected from Ojoo area in Ibadan, Oyo state, Nigeria. Two different types of compost - sheep-waste-sawdust (SPW-SD) and goat-waste-sawdust (GTW-SD) were applied to a soil at a rate $(0 \mathrm{~g}, 750 \mathrm{~g}, 450 \mathrm{~g})$. The result depicted that the contaminated soil experienced an enhanced natural bioremediation due to the applied bioremediation agents and the contaminated soil treated with SPW-SD gave best results. Samples remediated with SPW-SD and GTW-SD showed a Total Petroleum Hydrocarbon (TPH) removal efficiency of $55.4 \%$ and $7.9 \%$ respectively. Analysis showed that oil type, compost rate and period of application influenced the bioremediation process. From the results, composted organic waste application is a good and efficient way of remediating hydrocarbon impacted soil.
\end{abstract}

Keywords: compost, bio-remediation, hydrocarbon, soil, sheep-waste-sawdust, goat-wastesawdust

\section{INTRODUCTION}

Petroleum exploration and production has adversely affected the means of livelihood of most people in oil producing communities especially by degrading their farmlands. This study is focused on how to improve these farmlands in an environmental-friendly and cost-effective way. The objective of this study is to clean-up the environment, recycle organic waste, and determine the efficiency of animal waste in bioremediation.

Nigeria began searching for oil in 1937 [1]. Human activites and/or natural occurrences has therefore resulted to the release of petroleum hydrocarbon and its allied products into the environment. This spillage of oil mostly occur during oil exploration, transportation, and at storage facilities [2]. The dependant on diesel for powering of vehicles and generators can equally lead to spillage in the environment during transportation, cleaning of tanks and leakages from storage tank $[1,3]$. All these form of spillages lead to contamination of natural environment and degradation of the land around contaminated area. Also, contamination due to oil is known to alter the physical, chemical and biological properties of a soil $[4,5]$.

\footnotetext{
* Corresponding Author, email: adebolamay@gmail.com

(C) 2020 Alma Mater Publishing House
} 
Remediation is defined as the management of a site contaminant to prevent, reduce, or diminish damage to environment or human health which can lead to an accelerated reclamation of the affected lands [6, 7]. Biological, physical, and chemical procedures are employed for remediation, but this study focuses on biological process of remediation.

Bioremediation generates its name from biological remediation which is the degradation or transformation of contaminants into a non-hazardous or less hazardous chemicals. Degradation occurs during bioremediation when suitable microbes are present at the appropriate place with proper environmental condition [8, 9]. These microbes are bacteria and fungi with adequate metabolic and physiological capabilities to breakdwon the pollutant. Bioremediation unlike incineration or landfilling offers numerous advantages [5, 9] in the sense that it is less expensive, can be carried-out on site, and has minimal site disruption. Also, due to bioremediation, waste can be eliminated permanently and it has considerable public acceptance.

Organic waste such as agricultural waste, food waste, animal waste, and feaces are usually generated wherever human lives. Therefore as part of the effort to put this waste into use gave rise to compost technology for bioremediation process $[10,11]$. Composting is primarily the decomposition of waste which can either be aerobic or anaerobic. Aerobic means that the decomposition occurs in an oxygenated environment while anaerobic means that the decomposition happens in a non-oxygenated environment. This decomposition occurs as a result of naturally occurring micro-organisms such as bacteria and fungi. Composting can turn the organic waste into a rich dark coloured humus in just a few weeks.

The natural attenuation of crude oil from a polluted soil is slow and communities affected by oil spillage are denied access to agricultural lands for a long time, hence, bioremediation was brought about since processes used in decontaminating soil are limited in application and can be prohibitively or partially expensive [12, 13]. Bioremediation is becoming an increasing important method of waste treatment and it involves the introduction of nutrients as organic matter to the contaminated soil to boost the activity of micro organisms that upgrade the contaminant [14]. Bioremediation process enhances native bacteria through the addition of nutrients and oxygen to deteriorate petroleum hydrocarbon to water and carbon dioxide. The actual mechanism involved which is mediated by microbes is known as biodegradation $[15,16]$.

\section{EXPERIMENTAL SETUP}

The soil sample was collected from Ojoo area in Ibadan, Oyo State, Nigeria. It was a mixture of soil, various sizes of stones and some other materials which can be categorized as refuse as shown in Table 1. The sample was taken to screen house located at College of Environmental Management and Toxicology, Federal University of Agriculture Abeokuta, where it was separated by hand and soil which is the main research material was collected.

Table 1. Experimental design.

\begin{tabular}{|c|c|c|c|}
\hline S/N & Sample Code & Pot Composition & Replicate \\
\hline 1 & SSPO & SOIL+SPENT OIL+SPW-SD COMPOST 1100g & 3 \\
\hline 2 & GSPO & SOIL+SPENT OIL+GTW-SD COMPOST 1100g & 3 \\
\hline 3 & SPO & SOIL+SPENT OIL & 3 \\
\hline
\end{tabular}

where: SSPO - sheep waste compost and spent oil, SPW-SD - sheep waste and saw dust, GSPO - goat waste compost and spent oil, GTW-SD - goat waste and saw dust, SPO - spent oil

\subsection{Determination of sample $\mathbf{p H}$}

$10 \mathrm{~g}$ was weighed out from each of the $2 \mathrm{~kg}$ pot to be used for $\mathrm{pH}$ determination. This was dissolved in $20 \mathrm{~mL}$ of distilled water and shaken in a shaker for about 30 minutes. The $\mathrm{pH}$ values were read by dipping the tip of an electrode into the mixture of soil and water. The $\mathrm{pH}$ determination was done at the start and on a weekly basis throughout the period of the remediation process.

\subsection{Determination of percentage organic carbon and matter}

$0.5 \mathrm{~g}$ of the sample was weighed into a beaker; $10 \mathrm{~mL}$ of potassium dichromate $\left(\mathrm{K}_{2} \mathrm{CrO}_{7}\right)$ and $20 \mathrm{~mL}$ of concentrated sulphuric acid $\left(\mathrm{H}_{2} \mathrm{SO}_{4}\right)$ was added to it and allowed to cool. After cooling, $100 \mathrm{~mL}$ of distilled water was added to the sample and 8 drops of ferroin indicator was also added. Then, ferrous ammonium 
sulphate was used to titrate it and the volume of the sulphate used was noted for the calculation of the organic carbon and matter. The percentage organic matter and carbon was done for the samples and the compost before addition and weekly after the addition of the compost to the samples till the end of the remediation process.

\section{RESULTS AND DISCUSSION}

\subsection{Effect of remediation through the use of compost on the sample pH}

The $\mathrm{pH}$ value of each soil sample replicate was taken before and during the remediation process with GTW-SD and SPW-SD compost. The results are plotted in Figure 1. The $\mathrm{pH}$ value before remediation ranges from 6.1 to 6.8 and from 6.4 to 6.8 for samples treated with SPW-SD compost and GTW-SD compost respectively. In general, the $\mathrm{pH}$ values increased for both treatments. After the remediation period, samples treated with GTW$\mathrm{SD}$ had a $\mathrm{pH}$ value ranging from 7.53 to 7.59 while the one treated with SPW-SD had a $\mathrm{pH}$ value ranging from 8.15 to 8.22 . The overall effect of the compost technology applied to the samples resulted in an average $\mathrm{pH}$ value increase of $7.58 \%$ for samples treated with GTW-SD compost while the one treated with SPW-SD compost had an average $\mathrm{pH}$ vlaue increase of $20.19 \%$. Although, during the remediation period, fluctuation in $\mathrm{pH}$ value was observed. However, the rise in $\mathrm{pH}$ value suggests there is a reduction in the acid content of the contaminated soil through the addition of the compost and this shows the effectiveness of the remediation method applied to the soil.

Also, the presence of heavy metals such as copper, lead, and cadmium were investigated before and after the remediation process. It was observed that there was reduction in the heavy metals content for the compost treated samples. The results are plotted in Figures $2 \mathrm{a}, 2 \mathrm{~b}$, and 2c. On commencing the remediation process, copper, lead, and cadmium had values ranging from 12 to $62.25 \mathrm{mg} / \mathrm{kg}, 39.9$ to $64.45 \mathrm{mg} / \mathrm{kg}$, and 0.5 to $2.05 \mathrm{mg} / \mathrm{kg}$ respectively for the samples treated with GTW-SD compost while those treated with SPW-SD had values ranging from 15.7 to $57.2 \mathrm{mg} / \mathrm{kg}, 20.4$ to $128.85 \mathrm{mg} / \mathrm{kg}$, and 2.55 to $2.7 \mathrm{mg} / \mathrm{kg}$ for copper, lead, and cadmium respectively. At the end of remediation, samples treated with SPW-SD had a mean value of $20.57 \mathrm{mg} / \mathrm{kg}, 21.73$ $\mathrm{mg} / \mathrm{kg}$, and $2.4 \mathrm{mg} / \mathrm{kg}$ for the heavy metals respectively and those treated with GTW-SD had a mean value of $33.18 \mathrm{mg} / \mathrm{kg}, 39.8 \mathrm{mg} / \mathrm{kg}$, and $1.22 \mathrm{mg} / \mathrm{kg}$ for the heavy metals respectively. The percentage removal efficiency of lead, copper, and cadmium by the GTW-SD compost is $18.61 \%, 18.11 \%$, and $10.9 \%$ respectively while SPWSD compost had a percentage removal efficiency of $65.96 \%$ for lead, $8.75 \%$ for cadmium, and $35.6 \%$ for copper.

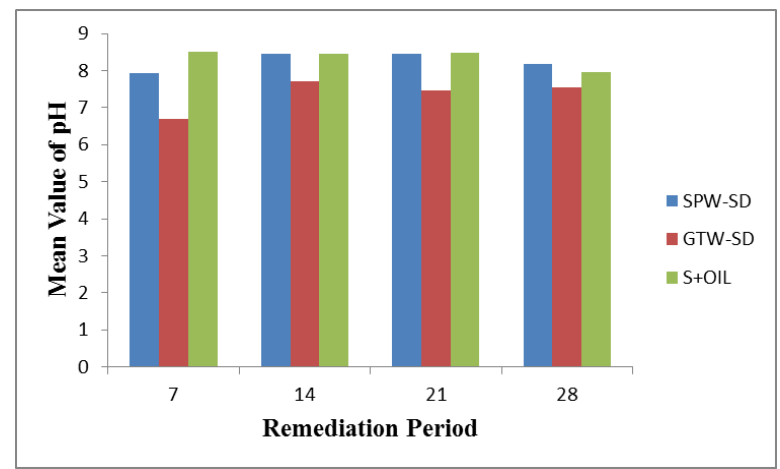

Fig. 1. Mean $\mathrm{pH}$ values for control and compost treated soil samples in relation to remediation period.

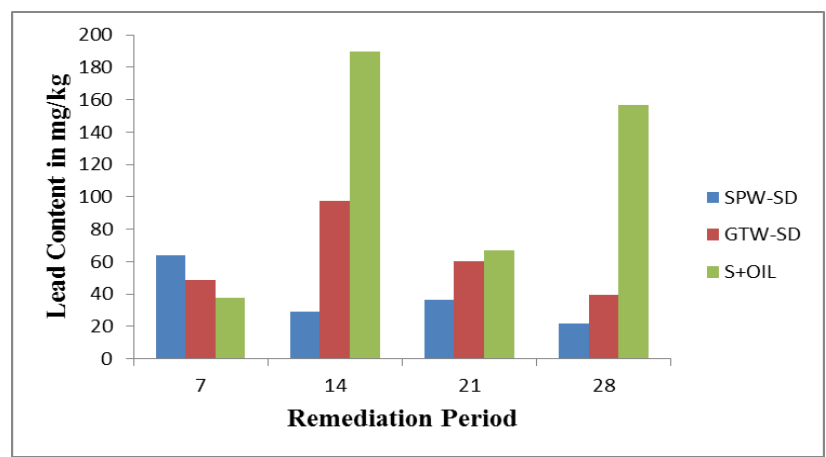

Fig. 2a. Lead content over the remediation period. 


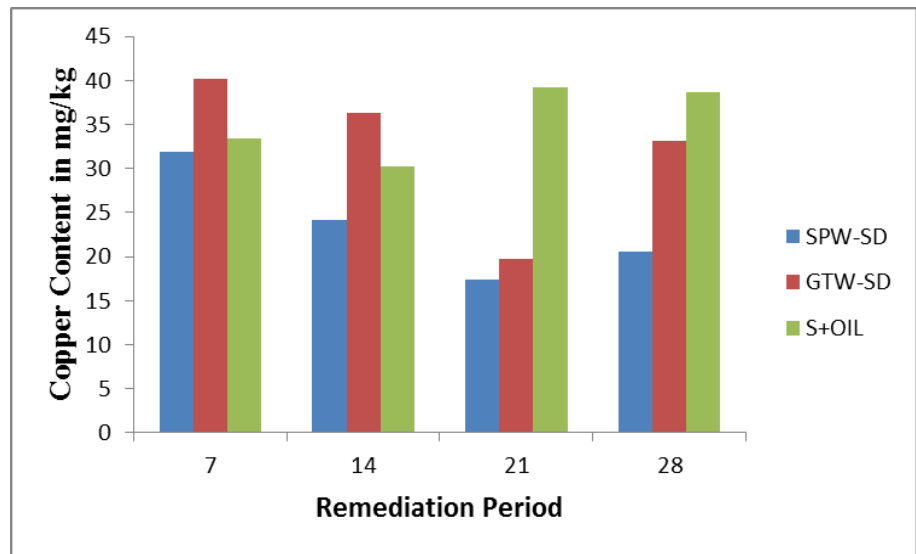

Fig. 2b. Copper content over the remediation period.

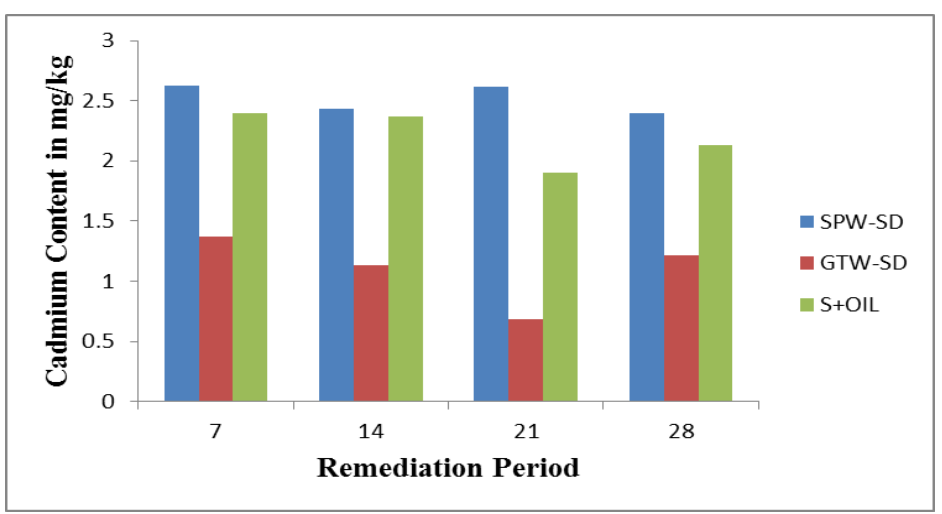

Fig. 2c. Cadmium content over the remediation period.

Furthermore, the percentage organic carbon (POC) of each soil sample replicate was determined before and during the treatment of the contaminated soil with GTW-SD and SPW-SD compost. The results are plotted in Figure 3. The POC range before remediation was from $2.7 \%$ to $3.2 \%$ for SPW-SD compost treated samples and $0.52 \%$ to $2.3 \%$ for GTW-SD compost treated samples. After remediation, the POC value increased for both treatment with that of SPW-SD treated samples ranging from 3.95\% to $4.07 \%$ and GTW-SD ranging from $3.47 \%$ to $3.95 \%$. In general, SPW-SD compost and GTW-SD compost treatment showed a total increase of $24.81 \%$ and $64.75 \%$ in the soil organic carbon respectively. Consequently, the contaminated soil experienced an increase in POC due to the compost material used in its treatment. Although, SPW-SD compost treated samples had a lesser percentage increment, but the efficiency of remediation is high as the SPW-SD compost has shown a greater consistency shown throughout the remediation process.

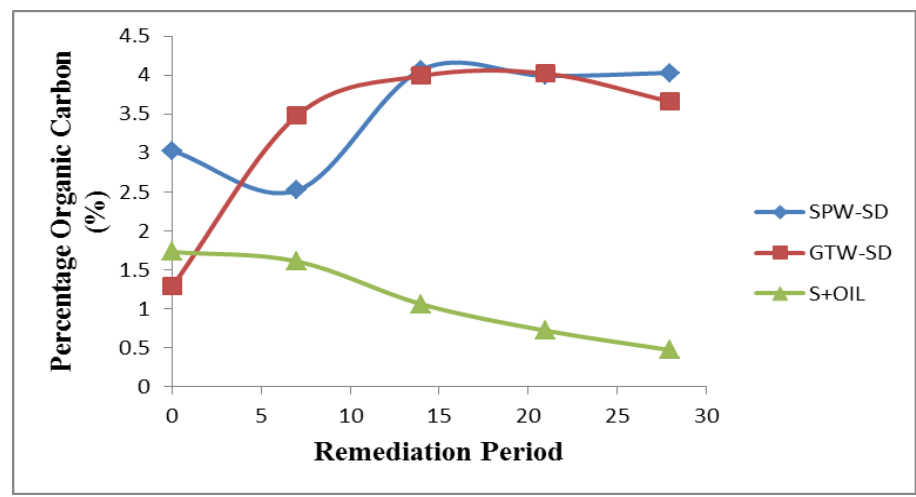

Fig. 3. Percentage organic carbon for control and compost treated soil samples in relation to remediation period.

\subsection{Effect of remediation through the use of compost on sample organic matter}

The percentage organic matter (POM) of each soil sample replicate was determined before and during the treatment of the contaminated soil with GTW-SD and SPW-SD compost. The results are plotted in Figure 4. The 
POM range before remediation was between $4.68 \%$ and $5.57 \%$ for SPW-SD compost treated samples and 0.89 to $3.9 \%$ for GTW-SD compost treated samples. After remediation, the POM value increased for both treatment with that of SPW-SD treated samples ranging from $6.81 \%$ to $7.02 \%$ and GTW-SD ranging from 5.98\% to $6.12 \%$. In general, SPW-SD compost and GTW-SD compost treatment showed a total increase of $24.89 \%$ and $65.23 \%$ in the soil organic carbon respectively. Consequently, after treatment, the contaminated soil experienced an increase in POM due to the compost material used in carrying out the remediation. Again. SPW-SD compost treated samples had a lesser percentage increment but as stated earlier, it has a high remediation efficiency.

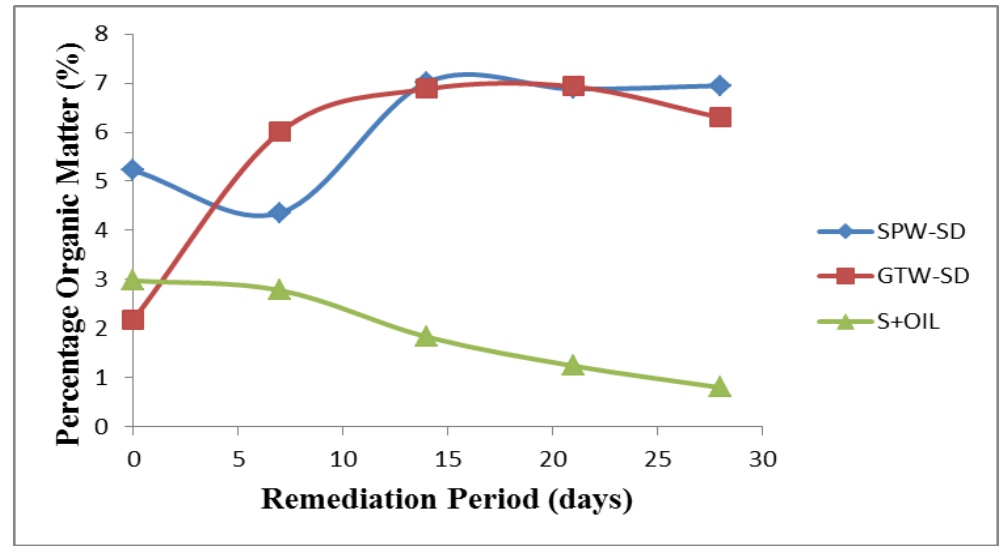

Fig. 4. Percentage organic matter for control and compost treated soil samples in relation to remediation period.

3.3. Effect of remediation through the use of compost on sample total petroleum hydrocarbon (TPH) In determining the effect of the compost remediation on the sample TPH, the TPH value of each soil sample replicate was taken before and during the treatment process with SPW-SD and GTW-SD compost. The results are plotted in Figure 5. The TPH value on commencement of the remediation process was around $415.15 \times 10^{3}$ and $195.28 \times 10^{3}$ for the samples treated with SPW-SD and GTW-SD compost respectively. It was observed that samples treated with SPW-SD compost experienced a decrease in TPH value while GTW-SD compost treated samples experienced an increase in TPH value at a later stage during its application as shown in Figure 5. Also, as depicted in Figure 5, the TPH value for both composts treated samples are almost similar at the end of the remediation period. Generally, the applied compost technology had a great effect on the contaminated soil samples with SPW-SD compost having a percentage degradation rate of 55.4\% and $7.9 \%$ for those treated with GTW-SD compost. The degradation of TPH was successful due to the significant reduction of TPH population observed during the process of bioremediation.

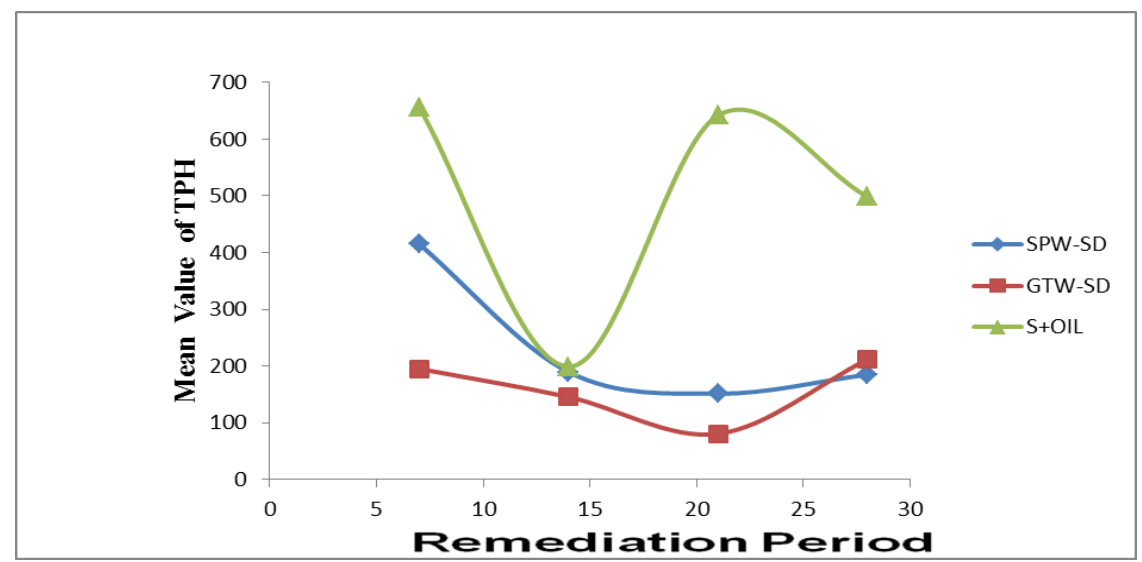

Fig. 5. Percentage total petroleum hydrocarbon reduction for control and compost treated soil samples in relation to remediation period.

\subsection{Effect of remediation through the use of compost on sample compactive effort}

The contaminated soil sample was subjected to a compaction test before and after remediation process. The Standard Proctor Compaction Test (ASTM-D698, Method A) was used and the results of the compaction tests are plotted in Figure 6. In general, there was reduction in dry density with increasing water content before the remediation process. After remediation, the maximum dry density for samples treated with SPW-SD compost 
was $1.46 \mathrm{~g} / \mathrm{cm}^{3}$ and $1.26 \mathrm{~g} / \mathrm{cm}^{3}$ for samples treated with GTW-SD compost. As shown in Figure 6 below, the contaminated soil has a reduced maximum dry density with increasing water content after treatment with both compost types.

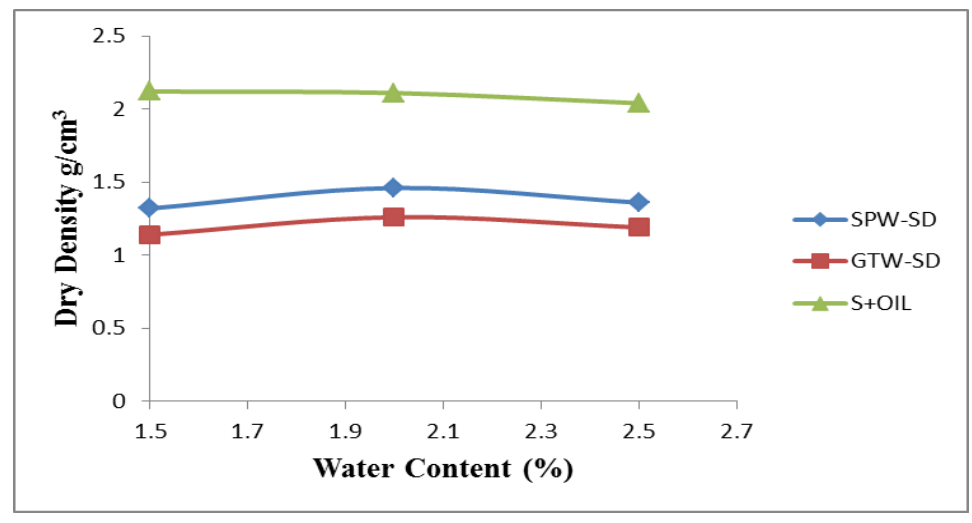

Fig. 6. Dry density versus percentage water content for untreated and treated soil sample.

\section{CONCLUSIONS}

Bioremediation using compost technology to enhance the biodegradation of spent oil in soil showed a satisfactory result. During 35 days of treatment, compost formed using sheep waste and saw dust shows a better total petroleum hydrocarbon degradation with a removal efficiency value of $55.4 \%$ as compared to $7.9 \%$ value showed by the goat waste-saw dust composted material. It also positively modified soil quality in terms of $\mathrm{pH}$, temperature, percentage organic carbon and matter, and the content of the heavy metals analysed. The reduction in optimum moisture content indicates the presence of excess oil in the soil before the remediation process. Analysis of heavy metals like lead, copper, and cadmium also shows a considerable reduction in their contents which is more indicating of the efficiency of the bioremediation methods used.

The application of composted organic waste is a good and efficient way of remediating spent oil contamination. It is also environmentally sound and not hazardous to human health.

\section{REFERENCES}

[1] Awobajo, S.A., An analysis of a spill incidence in Nigeria (1976-1980), Seminar on Petroleum Industry and the Nigerian Environment., NNPC/FMOW and Housing PT. Warri, 1981.

[2] Abii, T.A., Nwosu, P.C., The effect of oil-spillage on the soil of eleme in rivers state of the Niger-Delta area of Nigeria, Research Journal of Environmental Sciences, vol. 3, 2009, p. 316-320.

[3] Njoku, K.L., Akinola, M.O., Oboh, B.O., Phytoremediation of crude oil contaminated soil: the effect of growth of Glycine max on the physico-chemistry and crude contents of soil, Nature and Science, vol. 7, no. 10, 2007, p. 79-87.

[4] Odukwuma, L.O., Dickson, A.A.A., Bioremediation of crude oil polluted tropical mangrove environment, Bioline International Official Site, 2005,p. 1-6.

[5] Odu, C.T.I., The effects of nutrients application and aeration on oil degradation in soil, Environmental Pollution, vol. 15, 1978, p. 235-240.

[6] Odeyemi, O., Ogunseitan, O., Petroleum oil industry and its pollution potential in Nigeria, Oil and Petroleum Pollution, vol. 2, 1985, p. 223-229.

[7] Odu, C.T.I., Microbiology of soils contaminated with petroleum. Hydrocarbon extent of contamination and some soil and microbial properties affected after contamination, Journal of the Institute of Petroleum (London), vol. 58, 1972, p. 201-208.

[8] Ifeadi, C.N., Nwankwo, J., Oil spill incidents in Nigeria petroleum industry. A critical analysis, Napetcor, vol 8, 1980, p. 11-45.

[9] Gradi, P.C., Biodegradation. its management and microbiology basis. Biotechnology and Bio-Engineering, vol. 27,1985 , p. $660-674$. 
[10] Doelman, P., European perspectives of field research on bioremediation. Special attention to the Netherlands, The $5^{\text {th }}$ International Congress of Soil Science, 1994.

[11] Okpokwasili, G.C., Odokuma, L.O., Effect of salinity on biodegradation of oil spills dispersants, Waste Management, vol. 10, 1990, p. 141-146.

[12] Alexander, M., An introduction to soil microbiology, 2nd edition, John Wiley and Sons, New York, 1978, p. 223-330.

[13] Atlas, R.M., Bartha, R., Abundance, distribution and oil degradation potential of microorganisms in Raritan Bay, Environmental Pollution, vol. 4, 1973, p. 291-300.

[14] Atlas, R.M., Microbial degradation of petroleum: an environmental perspective, Microbiological Reviews, vol. 45, 1981, p. 180-209.

[15] Atlas, R.M, Horowitz, K., Bej, A.K., Response of microbial population to environment disturbance, Ecology, vol. 22, 1991, p. 249-256.

[16] Colwell, R.R., Walker, J.D., Ecological aspects of microbial degradation of petroleum in the marine environment, CRC Critical Reviews in Microbiology, vol. 5, no. 4, 1977, p. 423-445. 